\title{
TATA KELOLA DOKUMEN REKAM MEDIS SEBAGAI UPAYA MENJ AGA RAHASIA MEDIS DI PELAYANAN KESEHATAN
}

\author{
$J$ udi \\ STIKES HAKLI SEMARANG \\ yudi_hakdi@yahoo.co.id
}

\begin{abstract}
The purposes of this study are To know the barriers and solutions in the management of medical record documents as an effort to keep the medical secrets in health care unit. Research method used in this study is empirical normativejuridical, by using secondary data consists of primary legal materials, secondary legal materials, tertiary legal materials, and primary data as supporting data. This research uses descriptive analytical. The results of this study are; 1) Medical secrets are the patient's right which much be protected and upheld by all health care providers. 2) Violation of the rights of these patients is a crimethat can be sued by thelaw. The barrier found in this research is in real ity, many hospitals arelack of medical records staffs to manage the medical documents. The solution to this problemis to build heal th care partnership that puts the health providers and the health receivers in a partnership. Thesuggestion is the health care providers should hire professional medical record staffs for keeping the medical secrets.
\end{abstract}

Keywords: Medical Secrets, Documents, Health

\begin{abstract}
Abstrak
Tujuan penelitian ini adalah menggambarkan tata kelola dokumen rekam medis sebagai upaya menjaga rahasia medis di pelayanan kesehatan. J enis penelitian adal ah Yuridis Normatif Empiris, dengan menggunakan data sekunder yang terdiri dari bahan hukum primer, bahan hukum sekunder, bahan hokum tersier, dan data primer sebagai data pendukung. Spesifikasi penelitian ini Deskriptif. Hasil penelitian yang ditemukan; rahasia medis merupakan hak pasien yang harus dil indungi dan dijunjung tinggi oleh setiap penyelenggara pelayanan kesehatan. Pelanggaran terhadap hak pasien ini merupakan sebuah kejahatan yang dapat dimintai pertanggung jawaban hukum Hambatan : kenyataan sekarang yang dihadapi adalah masi h banyak rumah sakit kekurangan tenaga rekammedis untuk mengel ola dokumen medis. Solusi dari permasal ahan ini adalah melakukan pelayanan kesehatan partnership yang menempatkan health provider dan health receiver dalam suatu pola kemitraan (partnership). Saran,pelayanan kesehatan supaya mendayagunzkan tenaga rekammedis yang profesional untuk menyimpan rahasia medis
\end{abstract}

Kata Kund: Rahasia medis, dokumen, kesehatan

\section{PENDAHULUAN}

Asas legalitas merupakan sal ah satu prinsip utama yang dijadi kan dasar dal am setiap penyel enggaraan pemerintahan dan kenegaraan pada setiap negara hukum. Undang-undang dijadikan sebagai sendi utama penyel enggaraan kenegaraan dan pemerintah. Menyikapi hal ini dalam bidang kesehatan perlu diatur hukum Sasaran pengaturan tenaga kesehatan menekankan pada aspek syarat keahlian dan syarat kewenangan. Pemerintah mengakui secara faktual bahwa rangkaian tindakan petugas kesehatan ti dak sepenuhnya dapat ditangani sendiri, melainkan harus melibatkan tim kesehatan Iain. Rumah sakit sebagai institusi pelayanan kesehatan dimana semua profesi mempunyai peran dan tugas masingmasing. Setiap tindakan medik yang dilakukan merupakan suatu keputusan etik karena tindakan tersebut akan diberikan kepada manusia lain, yang umumnya memerlukan pertolongan. Keputusan etik harus memenuhi tiga syarat yaitu bahwa 
keputusan tersebut harus benar sesuai ketentuan yang berlaku, juga harus baik tujuan dan akibatnya dan keputusan tersebut harus tepat sesuai dengan konteks serta situasi dan kondisi saat itu, sehingga dapat di pertanggungj awabkan. Pel impahan wewenang dari aspek perdata adalah pemberian kuasa untuk atas namanya melakukan perbuatan sesuai batas kewenangan profesi yang dilakukan secara profesional dan menurut hukumadministrasi negara dil lakukan berdasarkan kewenangan atributif, mandat dan delegatif.

Penyel enggaraan upayakesehatan yang dilaksanakan oleh health provider mempunyai peluang besar untuk terjadinya berbagai konflik kepentingan dengan pasien. Konflik yang terjadi di picu oleh penerapan ilmu pengetahuan dan teknologi kedokteran dan kesehatan, oleh tenaga kesehatan untuk kepentingan diagnosa, pengobatan dan penyembuhan penyakit pasien. Penerapan ilmu pengatahuan dan tekhnologi kedokteran tersebut tidak semua berjalan dengan mulus sesuai dengan apa yang di harapkantetapi terkadang berdampak padamasal ah etika profesi dan hukum. Untuk mengantisipasi permasalahan yang dialami oleh health provider tersebut maka harus dilakukan pembenahan dari berbagai aspek pelayanan kesehatan yang bertujuan untuk meningkatkan mutu pelayanan kesehatan, memberikan perlindungan hukum bagi pasien dan masyarakat dan memberikan kepuasan atas jasa upaya kesehatanyang diterima oleh pasien. Hal yang pertamayang harus di benahi dal ampenyelenggaraan pelayanan kesehatan adalah pembenahan konsep atau paradigma pelayanan kesehatan dari para health provider. Dalam hal tersebut, perubahan paradigma pelayanan kesehatan haruslah kearah yang lebih sesuai dengan dinamika perkembangan sosial masyarakat dan hukum yang berlaku.Setiap instansi baik instansi pemerintah maupun swasta memiliki dokumen-dokumen penting yang harus tetap disimpan dan dijaga dengan baik, karena berkaitan langsung denganjal annya instansi tersebut, baik dalamhal kinerjasecarainternal maupun secara eksternal. Dokumen-dokumen tersebut juga sering dinamakan dengan istilah arsip atau file. Dalam dunia kedokteran arsip atau dokumen atau file sering disebut dengan istilah rekam medis. Rekam medis ini merupakan file-file tempat dimana keseluruhan keberadaan pasien beserta data-datayang di milikinya termasuk jenis penyakitnya, tercatat atau terekam dalam file-file tersebut.
Rekammedisini merupakan suatu sistempelayanan yang lebih efisien dan memungkinkan pengguna dapat memanfaatkan pelayanan yang diberikan dengan lebih efektif. Rumah sakit sebagai salah satu instansi yang berfungsi sebagai pusat pelayanan kesehatan bagi masyarakat sudah sepantasnya memberikan layanan tersebut. Dokumen-dokumen penting atau arsip atau rekam medis harus disimpan dengan sebaik-baik mungkin, agar jika arsip atau rekam medis terebut dibutuhkan kembali dapat ditemukan dengan mudah dan cepat sehingga pelayanana yang diberikan menjadi lebih efektif. Tujuan penelitian ini adalah melakukan anal isis tata keloladokumen rekammedis sebagai upayamenjaga rahasia medis di pelayanan kesehatan.

\section{METODE}

Metode penelitian ini adalah Yuridis Normatif Empiris, dengan menggunakan data sekunder yang terdiri dari bahan hukum primer, bahan hukum sekunder, bahan hukum tersier, dan data primer sebagai data pendukung. Spesifikasi penelitian ini Deskriptif analitis.

\section{HASIL DAN PEMBAHASAN}

\section{Sistem Penamaan Pasien}

Sistem penamaan rekam medis pada dasamya adalah untuk memberikan identitas kepada seorang pasien serta untuk membedakan antara pasien satu dengan pasien lainnya, sehingga mempermudah dalam memberikan pelayanan rekam medis kepada pasien yang datang berobat kerumah sakit. Penulisan nama pasien pada rekammedis; Nama pasien harus lengkap, minimal terdiri dari dua suku kata. Dengan demikian, ada beberapakemungkinan dalam penul isan nama pasienya itu: Nama pasien sendiri apabila sudah terdiri dari dua suku kata; Nama pasien sendiri dilengkapi dengan nama suami,bila seorang perempuan bersuami; Nama pasien sendiri dilengkapi dengan nama orangtua,biasanya nama ayah; Bagi pasien yang mempunyai nama keluarga/marga didahulukan dan kemudian diikuti dengan nama sendiri; Nama ditulis dengan huruf cetak dan mengikuti ejaan yang disempurnakan; Bagi pasien perempuan diakhir nama lengkap ditambahNy. Atau Nn.sesuai dengan statusnya; Pencantuman tite selalu diletakkan sesudah nama lengkap pasien; Perkataan tuan,saudara,bapak,tidak dicantumkan (DepkesRI, 2006). 


\section{Sistem Penomoran Rekam M edis}

Rekam medis pada hampir semua lembaga pelayanan kesehatan disimpan menurut nomor,yaitu berdasarkan nomor pasien masuk (admission number). Menurut Depkes RI (2008) sistem pemberian nomor pasien masuk (admission numbering system) yang umum dipakai yaitu: Pemberian nomor cara seri(serial numbering system). Dengan sistem ini setiap pasien mendapat nomor baru setiap kujungan kerumah sakit. J ikapasien berkunj ung lima kali, mendapatlimanomor yang berbeda. Semua nomor yang diberikan kepada pasien tersebut harus dicatat pada Kartu I ndeks Utama Pasien(KIUP) pasien yang bersangkutan.

Rekam medisnya disimpan diberbagai tempat sesuai nomor yang telah diperoleh. Pemberian nomor cara unit (unit numbering system). Sistem ini memberikan hanya satu unit rekam medis kepada pasien baik pasient ersebut berobat jalan maupun rawat inap. Pada saat seorang pasien berkunjung pertama kali kerumah sakit apakah sebagai pasien berobat jalan ataupun untuk dirawat,kepadanyadiberikan satu nomor (admittingnumber) yang akan dipakai selamanya setiap kunjungan berikutnya, sehingga pasien tersebuthanya mempunyai saturekammedisyang tersimpan dibawah satu nomor.

Pemberian nomor cara seriunit(serial unitn umbering system). Sistem ini merupakan gabungan antarasistem seri dan sistem unit. Setiap pasien yang berkunjung kerumah sakit diberikan satu nomor baru tetapi rekam medisnya yang terahulu digabungkan dan disimpan di bawah nomr yang paling baru sehingga terciptalah satu unit rekam medis. A pabila satu rekam medis lama diambil dan dipindahkan tempatnya kenomor yang baru,di tempat yang lama diberi tanda petunjuk yang menunjukkan kemana rekam medis tersebut dipindahkan.Tanda petunjuk tersebut diletakkan menggantikan tempat rekam medis yang lama. Dari ketiga macam sistem penomoran berdasarkan nomor pasien masuk tersebut, pemberian nomor cara unitlah yang lebih baik digunakan,karena dengan cara ini seorang pasien hanya memiliki satu nomor setiap kunjungan kerumah sakit,dan rekam medisnya baik rawat jalan maupun rawat inap terkumpul dal am satu map(folder) sehingga dengan cepat memberikan gambaran yang lengkapmengenai riwayat penyakit dan pengobatan seorang pasien kepada rumah sakitmaupun staf medis lainnya.Selain itu juga menghilangkan kerepotan mencari/mengumpulkan rekam medis pasien yang terpisah-pisah seperti pada sistem seri, menghilangkan kerepotan mengambil rekam medis lama untuk disimpan kenomor baru seperti dalam sistemseri unit.

\section{Sistem Penyimpanan Rekam M edis}

Berdasarkan Permenkes nomor 269/MENKES/PER/ III/2008 tentang rekam medis menyatakan bahwa dokumen rekammedis harus disimpan dengan tata cara tertentu, sehingga dokumen rekammedi s harus di kelola dan dilindungi agar aman dan terjaga kerahasiaannya. Dilihat dari pemusatan atau penyatuan dokumen dapat di bedakan menjadi 2 cara, yaitu: Sistem penyimpanan sentral isasi merupakan penyimpanan rekam medis seorang pasien dal amsatu kesatuan baik catatan-catatan kunjungan poliklinik maupun catatan-catatan selama seorang pasien di rawat dalam satu ruangan yang sama. Penggunaan sistem sentral isasi memiliki kebaikan dan jugakekurangannya. Dengancara desentralisasi terjadi pemisahan antararekammedis polikl inik dengan rekam medis penderita dirawat. Berkas rekam medis rawat jalan dan rawat inap disimpan tempat penyimpanan yang terpisah

\section{Upaya Menjaga Rahasia Medis di Pelayanan Kesehatan}

Rahasia Medik adal ah segal asesuatu yang dianggap rahasia oleh pasien yang terungkap dal am hubungan medis dokter-pasien baik yang diungkapkan secara langsung oleh pasien (subjektif ) maupun yang diketahui oleh dokter ketika melakukan pemeriksaan fisik dan penunjang ( objektif). Rahasia medis ini juga sering disebut sebagai rahasia jabatan dokter yang timbul karena menjalankan tugas profesional nya sebagai dokter. Rahasiamedismerupakan hak pasien yang harus dilindungi dan dijunjung tinggi oleh setiap penyel enggara pel ayanan kesehatan.

Pelanggaran terhadap hak pasien ini merupakan sebuah kejahatan yang dapat dimintai pertanggung jawaban hukum. Perlindungan terhadap hak rahasia medis ini dapat di lihat dalam peraturan perundang-undangan antara lai $n:$ Pasal 57 Undang - Undang Nomor 36 tahun 2009 tentang kesehatan mengatakan bahwa setiap orang berhak atas kondi si kesehatan pribadinya yang telah dikemukakan kepada penyelenggara pelayanan kesehatan. Pasal 
48Undang - Undang Nomor. 29 tahun 2004tentang Praktek kedokteran mengatakan bahwa setiap dokter atau dokter gigi dal ammelaksanakan praktek kedokterannyawajib menyimpan rahasia kedokteran. Pasal 32 (i) Undang - Undang Nomor 44 tahun 2009 Tentang Rumah Sakitmengatakan bahwahak pasien untuk mendapatkan privasi dan kerahasiaan penyakit yang diderita termasuk data-data medisnya.

Sesuai dengan ketentuan pasal 48 Undang - Undang Nomor 29 Tahun 2004 tentang Praktik Kedokteran ditetapkan sebagai berikut:

1. Setiap dokter atau dokter gigi dalam melaksanakan praktik kedokteran wajib menyimpan rahasia kedokteran.

2. Rahasia kedokteran dapat di buka hanya untuk kepentingan kesehatan pasien, memenuhi permintaan aparatur penegak hukum dalam rangka penegakan hukum, permintaan pasien sendi ri, atau berdasarkan ketentuan perundangundangan.

3. Dan pasal 51 huruf c Undang Undang Nomor 29 Tahun 2004adanyakewajibanmerahasiakansegala sesuatu yang di ketahuinya tentang pasien, bahkan jugasetel ah pasien itumeninggal dunia. Berkaitan dengan pengungkapan rahasiakedokteran tersebut diatur dal am pasal 10 ayat (2) Peraturan Menteri Kesehatan Nomor 269/Menkes/Per/I II /2008 Tentang RekamMedis sebagai berikut: Informasi tentang identitas, diagnosis, riwayat penyakit, riwayat pemeriksaan dan riwayat pengobatan dapat dibuka dal am hal :

a untuk kepentingan kesehatan pasien;

b. memenuhi permintaan aparatur penegak hukum dal am rangka penegakan hukum atas perintah pengadilan;

c. permintaan dan/atau persetujuan pasien sendiri;.

d. permintaan institusi/lembaga berdasarkan ketentuan perundang-undangan;

e dan untuk kepentingan penelitian, pendidikan, dan audit medis, sepanjang tidak menyebutkan identitas pasien.

Mengenai rahasia kedokteran dikenal adanya trilogi rahasia kedokteran yang meliputi persetujuan tindakan kedokteran, rekam medis dan rahasia kedokteran karena keterkaitan satu sama lain. J ika menyangkut pengungkapan rahasia kedokteran maka harus ada izin pasien (consent) dan bahan rahasia kedokteran terdapat dalam berkas rekam medis.

Pelanggaran terhadap ketentuan perundangundangan tersebut diancam pi dana kurungan badan sebagai mana yang diatur dalam pasal 322KUHP yang mengatakan : " barang siapa yang dengan sengaja membuka rahasia yang wajib ia simpan karena jabatannya atau karena pekerjaannya, baik yang sekarang maupun yang dahulu, dihukum dengan hukuman penjara sel ama-lamanya sembilan bul an atau denda sebanyak-banyaknya sembilan ribu rupiah. Rahasia medis ini hanya dapat dibuka oleh rumah sakit, dokter dan tenaga kesehatan lainnya dalamhal telahmendapatkan persetujuan dari pasien yang bersangkutan, demi untuk kepentingan orang banyak atau untuk kepentingan penegakan hukum

Sehubungan dengan kepentingan hukum, maka semua rahasia medis yang tertuang dalam rekam medik adalah menjadi hak sepenuhnya dari pasien yang bersangkutan dan oleh sebab itu maka berkas rekam medik perlu di jaga kerahasiaanya agar ti dak dengan mudah di baca oleh pihak-pihak yang tidak berkompeten untuk mengetahui rahasiamedis pasien tersebut. Beberapa negarayang menganut kebebasan mutlak melaksanakan perlindungan rahasia medik dengan sangat ketat, sehi ngga rekammedik menjadi sangat konfidensial. Seorang suami tidak dengan mudah mendapatkan isi rekam medik istrinya ataupun sebal iknyajika oleh suami atau istri tersebut menyatakan bahwa hal tersebut konfidens bagi pasangannya Sebegitu ketatnya perlindungan rahasia medis tersebut, terkadang sampai meninggal pun rahasia tersebut tetap tersi mpan rapi.

Kendala dan Solusi Tata Kelola Dokumen Rekam Medis Sebagai Upaya Menjaga Rahasia Medis di Pelayanan Kesehatan

Kendala Tata Kelola Dokumen Rekam Medis Sebagai U paya M enjaga Rahasia M edis di Pelayanan Kesehatan

Hasil wawancara peneliti dengan kepala bagian rekam medis di rumahsakaitRAA Soewondo Pati di dapatkan bahwa ada seorang pasien lama yang sudah 10 tahun tidak berkunjung kerumah sakitkarena pi ndah domisili ke luar kota, pasien tersebut datang dan bermaksud meminta salinan/foto copy dokumen rekam medisnya untuk keperluan pengobatan di tempat tinggal yang 
baru. Seiring dengantuntutanterhadapsistempelayanan di rumah sakit, maka sudah seharusnya setiap rumah sakit memiliki arsip atau rekam medis harus disimpan dengan sistem yang baik dal am upaya memperlancar pelayanan kesehatan yang diberikan kepada pasien. Keberadaan tenaga rekam medis sangat membantu dalam melayani pasien ataupun pengunjung. Tetapi kenyataan sekarang yang dihadapi adalah kurangnya tenaga rekammedis. Hal ini dapat mengganggu sistem pelayanan di rumah sakit.

Penggunaan alat-alat berteknologi tinggi seperti komputer sangat membantutenaga rekammedis dalam menjalankan tugasnya. selain mempermudah tugas seorang rekam medis al at-alat el ektronik (komputer) yang mendukungakan memudahkan pengumpulan dan pencarian data-data pasienji ka di butuhkan oleh seorang dokter secaracepat dapatditemukan. Setiapinstansi baik instansi pemerintah maupun swastamemiliki dokumendokumen penting yang harus tetap disimpan dan dijaga dengan baik, karena berkaitan langsung dengan jalannya instansi tersebut, baik dal amhal kinerja secara internal maupun secara eksternal. Dokumen-dokumen tersebut juga sering dinamakan dengan istilah arsip atau file. Dalam dunia kedokteran arsip atau dokumen atau file sering disebut dengan istilah rekam medis. Rekam medis ini merupakan file-file tempat dimana kesel unuhan keberadaan pasien beserta data-data yang dimilikinya termasuk jenis penyakitnya, tercatat atau terekam dalam file-file tersebut. Rekam medis ini merupakan suatu sistem pelayanan yang lebih efisien dan memungkinkan pengguna dapat memanfaatkan pelayanan yang diberikan dengan lebi h efektif. Rumah sakit sebagai salah satu instansi yang berfungsi sebagai pusat pelayanan kesehatan bagi masyarakat sudah sepantasnya memberikan layanan tersebut. Dokumendokumen penting atau arsip atau rekam medis harus disimpan dengan sebaik-baik mungkin, agar jika arsip atau rekam medis tersebut di butuhkan kembali dapat ditemukan dengan mudah dan cepat sehinggapel ayanan yang di berikan menjadi lebih efektif.

\section{Solusi Tata K elola Dokumen R ekam M edis Sebagai Upaya M enjaga di Pelayanan Kesehatan.}

Solusi dari permasalahan ini adalah melakukan pelayanan kesehatan partnership yang menempatkan health provider dan health receiver dalam suatu pola kemitraan (partnership). Pola kemitraan ini akan menempatkan heal th provider dan heal threceiver dalam suatu hubungan kontraktual (kontrak terapeutik) yang masing-masing pihak mempunyai hak dan kewajiban untuk saling dihargai dan di hormati.. Hubungan kontraktual ini tidak lain adal ah sebuah hubugan hukum yang dampak hukum. Pelayanan partnership ini akan menempatkan masing-masing pi hak berada dalam kesetaraan dalam pengambilan keputusan terhadap suatu tindakan medik atau pengobatan dan perawatan yang akan dilakukan oleh health provider terhadap healthreceiver. Pengingkaran terhadap pola pelayanan partnershi p ini akan merusak keharmonisan hubungan kontrak terapeutik yang tentunya dapat berimplikasi hukum.

Pengembangan pola partnership ini adalah dalam bentuk pelaksanaan informed consent yang merupakan penghargaan akan hak-hak asasi pasien. Health provider berkewaji iban untuk mendapatkan persetujuan (izin) dari pasien terhadap apa saja yang akan dilakukannya dalam memberkan pelayanan medik. Tindakan tanpaijin adal ah perbuatan mel anggar hukum yang dapat di gugat atau di tuntut secara perdata atau pi dana akibat kerugian yang dialami pasien. Penyebab utama konflik medis dalam pelayanan kesehatan adalah ketidak puasanyang dialami ol eh pasien atas pelayanan kesehatan yang diterimanya dari health provider. Ketidak puasan tersebut terjadi akibat rendahnya mutu pelayanan kesehatan rumah sakit yang cederung menelantarkan pasien, tidak memberikan informasi medis yang jelas, bertindak arogan dengan tidak menghargai hak-hak pasien , tinggi nya biayatindakan dan perawatan medis yang di tanggung pasien dan lamanya hari perawatan yang harus di lal ui ol eh pasien dalam suatu waktu perawatan.Untuk meminimalisasi konflik medis tersebut, maka secara dini harus disadari bahwa pelayanan kesehatan yang disel enggarakan oleh health provider telah mengalami sebuah babak baru, yaitu pelayanan kesehatan yang tidak hanya berupa sebuah hubungan moral dan hubungan medis, tetapi telah bergeser kearah hubugan hukum yang dapat berakibat hukum Perubahan paradigma pelayanan kesehatan sebagai sebuah langkah awal untuk mencegah terjadinya konflik dokter-pasien.

\section{SIM PULAN}

Pada dasarnya jika arsip atau rekam medis tidak tersimpan dalam satu tempat atau tidak ada sistem yang mengatur penyimpanannyamakaakan berdampak terhadap pelayanan yang diberikan, seperti akan memperlambat pelayana dan tenaga yang di butuhkan dalam akan bertambah untuk mecari arsip atau berkas tersebut. 


\section{DAFTAR PUSTAKA}

Hardijan Rusli, 2006. MetodePenelitian Normatif: Bagaimana? “Law Review, Fakultas Hukum Universitas Pelita Harapan

Soerjono, Soekanto dan Sri mamudji, 2009, Penel itian Hukum Normatif Suatu Tinjauan Singkat Cetakan Kesembilan, PT Raja Grafindo Persada, Jakarta

Basuki, Sulistyo, 2003. Manajemen Arsip Dinamis. Gramedia Pustaka Utama:J akarta

Departemen Kesehatan RI Direktorat J enderal Pelayanan Medik, (1997), Pedoman Penyelenggaraan RekamMedis Rumah Sakit di Indonesia, Jakarta

Hatta. G R., (2009), Pedoman Manajemen Informasi Kesehatan Di Sarana Pelayanan Kesehatan, J akarta: Universitas I ndonesia (UI Press)

KEPMENKES RI No.129/MENKES/SK/II/2008 tentang Standar Pelayanan Minimal Rumah Sakit
Pratiwi. Yulia Dirgantari, FKM UI, 2009, Anal isis Kelengkapan Pengisian ResumeMedis Rawat Inap Rumah Sakit Budi Kemuliaan Tahun 2008-2009.

Undang-undang No. 36 Tahun 2009 tentang Kesehatan (Lembar Negara RI Nomor. 144 tahun 2009, Tambahan Lembaran Berita Negara Nomor 5063)

Peraturan Menteri Kesehatan (PERMENKES) Nomor 269/MENKES/PER/III/2008 tentang RekamMedis

Undang-Undang Nomor 29 Tahun 2004 tentang Praktik Kedokteran

Undang-Undang Nomor 44 Tahun 2009 tentang Rumah Sakit

Peraturan Menteri Kesehatan Nomor 269/MENKES/ PER/III/2008 tentang Rekam Medis 
J urnal Manajemen I nformasi Kesehatan I ndonesia Vol . 5 No.1 Maret 2017

ISSN: 2337-6007 (online); 2337-585X (Printed) 